\title{
Abdominal bandage after colic surgery - sense or nonsense?
}

\author{
Astrid B. M. Rijkenhuizen
}

\begin{abstract}
Summary
A prospective controlled, randomised clinical trial was initiated to evaluate the effect of abdominal wall bandaging with an elastic and strong adhesive material on the incidence on post-operative complications following colic surgery through a midline celiotomy. 188 Horses were included, that ad random were assigned into 2 groups based on the application of an abdominal bandage. The horses included survived at least 1 month after surgery and had adequate medical records. The post-operative incisional complications short term and long term were recorded. It was hypothesized that the application of an abdominal bandage following colic surgery through a midline celiotomy incision would significantly reduce the incidence of post-operative incisional complications. The application of a bandage had a significant positive effect in preventing postoperative edema $(P<0.05)$ : the horses with a bandage developed edema in $23.4 \%(n=23)$ and the horses without a bandage in $51.1 \%(n=45)$ of the cases. Wound discharge (transudate and purulent) occurred in $22 \%$ ( $n=38$ ) of the horses. A slight effect of the bandage, although not significant, was found on wound discharge; in the group of horses with a bandage more transudative wounds were noticed: $11.2 \%(n=11)$ versus $6 \%(n=5)$. No difference was found in the number of horses with purulent discharge: $12(n=12)$ versus $11 \%(n=10)$ and total wound dehiscence did not occur. Of the 188 patients $13.9 \%(n=25)$ of the horses developed a hernia and no difference in the frequency of occurrence of hernias as well the size of the hernia between the 2 groups was found. In conclusion: the use of bandages does not reduce the incidence of wound dehiscence and no effect was obtained in preventing incisional hernias. The application of a bandage postoperative has no advantages on wound healing other than preventing edema.
\end{abstract}

Schlüsselwörter: Horse / equine / colic / surgery / abdominal bandage / laparotomy / celiotomy / incisional complications

\section{Ist ein Bauchverband nach der Kolikoperation sinnvoll?}

Ein prospektiver, randomisierter klinischer Versuch wurde initiiert, um den Einfluss einer Bauchbandage aus elastischem stark klebendem Material auf die Inzidenz von postoperativen Komplikationen nach einer aufgrund von Kolik über die Mediane durchgeführten Laparotomie. Die Studie umfasste 188 Pferde, welche in Abhängigkeit von dem Anlegen einer Bauchbandage per Zufall in zwei Gruppen aufgeteilt wurden. Die Pferde der Studienpopulation überlebten den chirurgischen Eingriff über einen Monat und ihre medizinischen Akten waren vollständig. Erfasst wurden sowohl die die Inzision betreffenden Kurzzeit- als auch Langzeit - Komplikationen. Es wurde angenommen, dass durch das Anlegen einer Bauchbandage die postoperativen Komplikationen im Bereich der Inzision nach einer Laparotomie über die Mediane aufgrund einer Kolik signifikant reduziert werden können. Das Anlegen der Bauchbandage hatte einen signifikant positiven Einfluss auf die Verhinderung eines postoperativen Ödems $(P<0,5)$ : Pferde mit einer Bauchbandage entwickelten zu 23,4\% $(n=23)$ ein Ödem und Pferde ohne Bauchbandage zu 51,1\%(n=45). Wundsekretion(Transsudat und purulent) trat bei 22\%(n=38) der Pferde auf. Es zeigte sich ein geringgradiger Einfluss der Bandage in Hinblick auf die Wundsekretion, allerdings war dieser nicht signifikant; in der Gruppe von Pferden mit Bauchbandage wurde mehr Transsudat beobachtet: 11,2\%(n=11) versus 6\%( $n=5)$. Kein Unterschied wurde bei der Anzahl der Pferde mit purulenter Sekretion nachgewiesen: $12 \%(n=12)$ versus $11 \%(n=10)$, eine totale Nahtdehiszenz trat nicht auf. Von den 188 Patienten entwickelten 13,9\%(n=25) der Pferde eine Hernie und weder in Hinblick auf die Häufigkeit noch auf die Größe konnte zwischen den beiden Gruppen ein Unterschied festgestellt werden. Zusammenfassend: Die Verwendung einer Bandage reduziert nicht die Inzidenz einer Nahtdehiszenz und durch sie konnte das Auftreten einer abdominaler Hernie der Inzision nicht verhindert werden. Das postoperative Anlegen einer Bandage hat keine Vorteile für die Wundheilung mit Ausnahme der Verhinderung eines Ödems.

Keywords: Pferd / Bauchverband / Kolik / Chirurgie / Laparotomie / Wundkomplikationen / Wundheilungsstörung

\section{Introduction}

Incisional complications after colic surgery occur frequently varying from edema, infection, hernias and wound dehiscence. A large scale of pre-surgical and surgical factors considered to be of influence are patient age, length of procedure, suture material, suturing techniques and contamination (Wilson et al. 1989, Becker 1995, Bartmann et al. 2003, Coomer et al. 2007, Smith et al. 2007, Anderson et al. 2011 ). Also post-operative risk factors like fever, postoperative pain (rolling), coughing and immunosuppression due to concurrent illness (hypoproteinemia, respiratory complications, leukopenia, diarrhoea, peritonitis) are known to increase the incidence of complications. All factors which could result in an inability of the sutured abdominal wall to withstand the intra-abdominal pressure. Identification of the risk factors is important as well as the development of a method to prevent complications.
The purpose of this study was to evaluate the effect of abdominal wall bandaging with an elastic and strong adhesive material (Elastoplast ${ }^{\circledR 1}$ ) on the incidence on post-operative complications following colic surgery through a midline coeliotomy. Additionally, the association between some risk factors and the occurrence of postoperative complications were evaluated.

\section{Materials and methods}

The medical records of 188 horses, operated on for colic through a right ventral celiotomy, at the Department of Equine Sciences were reviewed by one person. They ranged in age from 1 month to 20 years (average 7.4 years). The horses were ad random divided into 2 groups based on the application of an abdominal bandage. The horses included 
survived at least 1 month after surgery and had adequate medical records. Horses that needed a relaparotomy were excluded from the study. Group 1 (98 patients) received an abdominal bandage, whereas group 2 (90 patients) was left without a bandage.

Each patient was positioned in dorsal recumbency, the abdomen was clipped and aseptically prepared for surgery with $2 \%$ chlorhexidine gluconate and 70\% isopropyl alcohol. The abdomen was opened by a midline celiotomy, cranial of the umbilicus. The peritoneal cavity was entered by blunt dissection and a surgical ring drape (Vidrape ${ }^{T M} 2$ ) positioned to protect the incision. The incision was closed in four layers. The peritoneum that had been split longitudinally when the abdomen was entered initially, was closed in a simple continuous pattern with polyglactin 910 (Vicryl 0 USP, Ethicon). The linea alba was closed using a continuous suture (Vicryl 6 USP as a single strand or 4 as a double strand). The suture was started and tied beyond the extremities of the incision. Four to five throws were used in each knot. The subcutaneous tissue was sutured in a simple continuous pattern (Vicryl 2-USP) and the skin with a continuous intradermal (Vicryl 2-0) or a simple interrupted suture (monofilamentous Polyamid; Ethilon 0 USP, Ethicon). Because all surgeons (seven) used basically the same method of wound closure, the effect of the suture material and suturing pattern used was not evaluated.

The horses were administered peri-operative antibiotics (gentamicin $6.6 \mathrm{mg} / \mathrm{kg}$ IV once daily and procaine penicillin $25.000 \mathrm{IU} / \mathrm{kg}$ intramuscularly IM once daily). Flunixin meglumine $(1.1 \mathrm{mg} / \mathrm{kg}$ IVtwice daily) was administered intraoperatively and for 2-3 days postoperatively. All horses underwent the same peri- and post-operative management.

At the end of the surgical procedure, the skin was desinfected with Betadine ${ }^{3}$. Then, a sterile gauze was attached to the wound with adhesive tape. Immediately, after recovery, the tape and gauze were removed, again the skin was desinfected and a sterile woundpad (Cutisorb ${ }^{4}$ ) was put on the wound. The adhesive elastic bandage (Elastoplast) was applied tightly around the belly and left in position for 10 days (figures 1+2).

Information collected included the following:

- presurgical factors: age of the horse, breed, gender

- surgical factors: the identity of the primary surgeon, the length of anaesthesia (which is an indication of the length of the surgical procedure), administration of antibiotics, intestinal segment involved, wound classification, the result of bacterial culture of the abdominal fluid obtained at the end of the surgery.

- postsurgical factors: edema formation at the surgical site, wound discharge, herniation, wound dehiscence. Wound evaluation took place daily until the horses were discharged. In the control group, the wound was inspected daily by direct observation and palpation. In the group horses with a bandage the area outside the bandage was inspected visually and the wound by palpation underneath the bandage.

Information was categorised in order to facilitate analyses. The horse ages were recorded in years. To evaluate the effect of age the horses less than one year of age were grouped together and compared to the older horses. Breeds were categorised as Thoroughbreds, Warmbloods, Coldbloods and ponies. Genders were recorded female, stallion, or gelding. Intestinal segment involved was recorded as involving the small intestine, large intestine and others.

The duration of surgical procedures were obtained from anaesthetic reports. The surgical procedure was classified as clean, clean-contaminated, contaminated and dirty, using the guidelines of the National Research Councel (1964).

The edema of the wound itself and the area around it were classified in 4 categories varying from no swelling to severe swelling. The swelling left a visible indentation after digital pressure. The incisional discharge was classified in 3 categories: no discharge, transudate and purulent discharge. The presence of a hernia (a palpable defect in the ventral body wall at the surgical site) was noted. Fatal acute dehiscences did not occur.

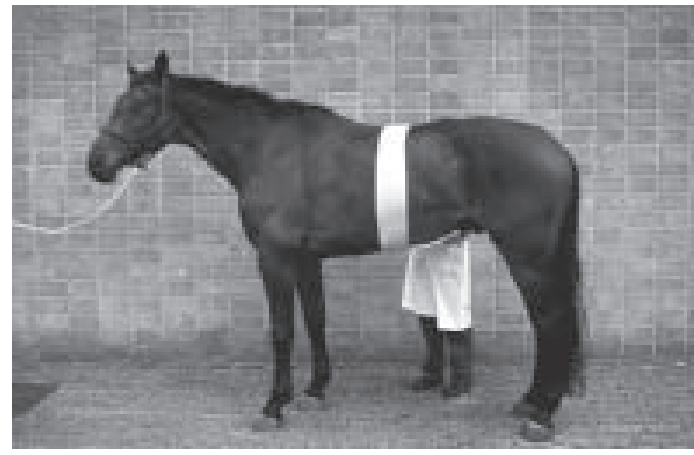

Fig. 1 Application of the Elastoplast around the belly of the horse over the cutisorb.

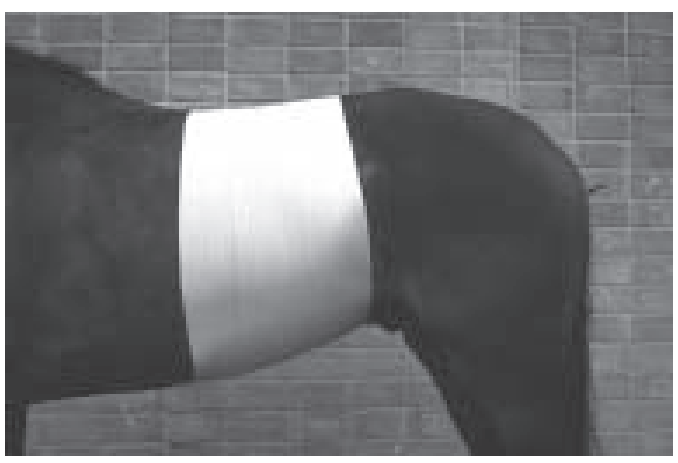

Fig.2 Abdominal bandage applied

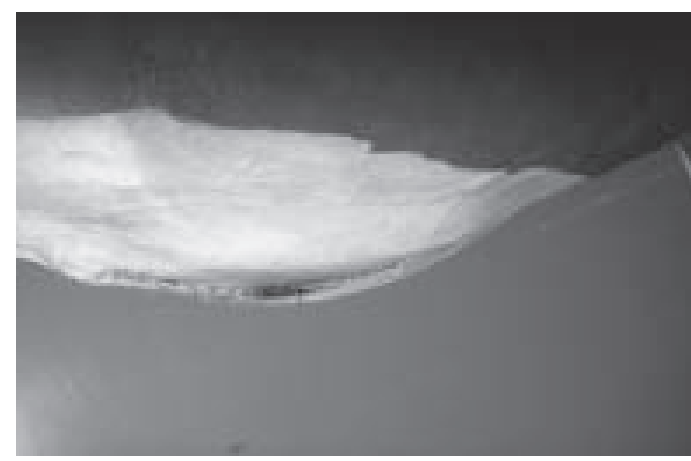

Fig.3 Edema formation peri-incisional and purulent drainage. On the left the head of the horse 
Follow-up information was obtained 1-2 years after discharge by phone-contact with the owner and specifically the owners were asked to palpate the belly of the horse; therefore also small invisible hernias are included.

\section{Statistics}

Statistical analyses included descriptive summary statistics and a logistic regression test. Variables included age, breed, gender, anaesthetic time, intestinal segment involved, and wound edema, wound discharge and herniation (frequency of occurrence of hernias and the size of the hernia). Because postoperative edema is considered normal (Anderson et al. 2011), only obvious and excessive edema (category 3 and 4) were taken into account as a variable. Significance was set at $P$ $<0.05$. A Pearson's chi-square test was performed to evaluate the association between bandage and incisional complications. An independent sample t-test was used to assess if there was an association between the mean time the bandage and outcome. The significance was also set at a $P$ value of $<0.05$.

\section{Results (Table 1 and 2)}

\section{Population}

The patients were ad random divided and no differences were present concerning the presurgical and surgical factors between the 2 groups.

The medical records of horses $(n=188)$ that met the inclusion criteria were evaluated (106 mares, 82 stallions and gel- dings). The mean age of the horses in group $1(n=98)$ was $7.4 \pm 5.2$ years and group $2(n=90) 6.6 \pm 4.9$ years with a range $0-30$ years. Breeds included Thoroughbreds $(n=36)$, Warmbloods $(n=127)$, Coldbloods $(n=4)$, ponies $(n=21)$.

\section{Effect of abdominal bandaging on wound healing}

The results are listed in Table 1 and 2 .

The application of a bandage had a significant positive effect in preventing postoperative edema $(P<0.05)$ : the horses with a bandage developed edema in $23,4 \%(n=23)$ and the horses without a bandage in $51.1 \%(n=45)$ of the cases. Wound discharge (transudate and purulent) occurred in $22 \%(n=38)$ of the horses. A slight effect of the bandage, although not significant, was found on wound discharge; in the group of horses with a bandage more transudate wounds were noticed: $12.2 \%(n=11)$ versus $5.6 \%(n=5)$. No difference was found in the number of wounds with purulent discharge: $12(n=12)$ versus $11 \%(n=10)$ and no total wound dehiscence occurred. Partial wound dehiscence occurred only in the horses with purulent discharge: 3 (3.1\%) versus 2 (2.7\%).

No difference was found in wound discharge for gender and the bandage in female and male horses remained dry, meaning was not urinated on.

Of the 188 patients $13.9 \%(n=25)$ of the horses developed a hernia and no difference in the frequency of occurrence of hernias as well the size of the hernia between the 2 groups was found. The herniation varied in size from $1.5 \mathrm{~cm}$ (finger size) to $25 \mathrm{~cm}$.

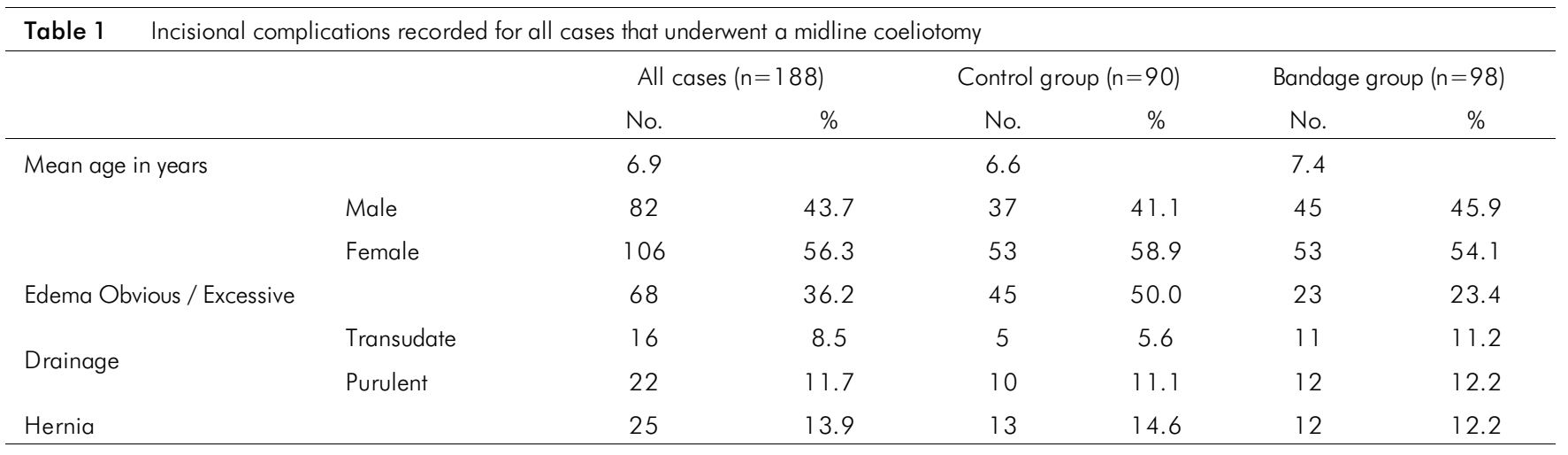

Table 2 Intestinal segment involved and wound complications in relation to total number of horses included and development of a hernia recorded for all cases and per group.

\begin{tabular}{|c|c|c|c|c|c|c|c|c|c|c|}
\hline & & & \multirow{2}{*}{\multicolumn{2}{|c|}{ All cases $(n=188)$}} & \multicolumn{6}{|c|}{ Hernias $(n=25)$} \\
\hline & & & & & \multicolumn{2}{|c|}{ All Hernias $(n=25)$} & \multicolumn{2}{|c|}{ Control group $(n=13)$} & \multicolumn{2}{|c|}{ Bandage group $(n=12)$} \\
\hline & & & No. & $\%$ & No. & $\%$ & No. & $\%$ & No. & $\%$ \\
\hline \multirow{3}{*}{\multicolumn{2}{|c|}{$\begin{array}{l}\text { Localization } \\
\text { colic cause }\end{array}$}} & Small intestine problem & 88 & 46.8 & 6 & 24.0 & 2 & 2.3 & 4 & 4.1 \\
\hline & & Large intestine problem & 98 & 52.1 & $19^{*}$ & 76.0 & 10 & 12.5 & 9 & 9.2 \\
\hline & & Others & 2 & 0.01 & 0 & 0 & 0 & 0 & 0 & 0 \\
\hline \multirow{5}{*}{ Wound } & \multirow{2}{*}{ Edema } & No edema/slight edema & 120 & 63.8 & 11 & 44.0 & 6 & 46.2 & 5 & 41.7 \\
\hline & & Obvious/Excessive & 68 & 36.2 & 14 & 56.0 & 7 & 53.8 & 7 & 58.3 \\
\hline & \multirow{3}{*}{ Discharge } & No discharge & 150 & 79.8 & 11 & 44.0 & 6 & 46.2 & 5 & 41.7 \\
\hline & & Transudate & 16 & 8.5 & 2 & 8.0 & 1 & 7.6 & 1 & 8.3 \\
\hline & & Purulent & 22 & 11.7 & 12 & 48.0 & 6 & 46.2 & 6 & 46.2 \\
\hline
\end{tabular}


Association between some risk factors and the occurrence of the development of a postoperative hernia.

Presurgical factors

In ponies (21 of the 188) no hernias occurred $(P<0.05)$, whereas in the group of horses the development of a hernia was not associated with breed. No relation was found in the frequency of occurrence of hernias with gender. Twelve mares developed a hernia and 13 males. Significantly $(P<0.05)$ more hernias were found in horses of one year and younger than in the older horses.

\section{Surgical factors}

The intestinal segment involved was significantly $(P<0.05)$ of influence. More hernias were diagnosed in horses with colic related to the large intestine. Fourty-seven \% of the horses $(n=88)$ had a small intestine problem of which $6.8 \%(n=6)$ developed a hernia. Fifty-two \% $(n=98)$ of the horses had a large intestine problem of which $19.4 \%(n=19)$ developed a hernia; the remaining 2 horses had no herniation. An additional factor is the influence of the surgeon, of which the effect was significant $(P<0.05)$. Variables that were not associated with the incidence of hernias were the length of the surgical procedure, administration of antibiotics, wound classification, and the bacterial isolates obtained of the abdominal fluid.

Post-surgical factors

A significant positive relation $(\mathrm{P}<0.05)$ was found between the extension of the edema, the presence of wound discharge and the development of hernias. Hernias occur more frequently in wounds with edema and with purulent discharge. Of the wounds with obvious/excessive edema developed $21 \%$ (14 of the 68) a hernia against $9 \%$ (11 of the 120) of the wounds without or slight edema. Fifty-four $\%$ of the horses with wounds with purulent discharge developed a hernia, and $8 \%$ of the horses with no discharge.

\section{Discussion}

Information in veterinary literature on the frequency of post operative wound complications after colic surgery is limited. Colic surgery can be classified as a clean wound (non traumatic, uninfected operative wounds in which the gastrointestinal tracts were not entered), clean-contaminated (operative wounds in which the gastrointestinal tracts was entered, but without unusual contamination) or contaminated (operative wounds in which the gastrointestinal tracts was entered, with contamination).

The application of the bandage had a significant effect in preventing edema post-operatively, and no effect in preventing purulent discharge and herniation. The occurrence of incisional drainage (20.2\%) was comparable to other authors (1638\%) (Kobluk et al. 1988, Gibson et al. 1989, Honnas and Cohen 1997, Ingle-Fehr et al. 1997, Bartmann et al. 2003, Smith et al. 2007). Partial wound dehiscence occurred only in those horses that showed purulent discharge. No difference in the frequency of occurrence of herniation between the 2 groups was found. In the bandage group 12 horses (13\%) had a hernia and in the other group 13 horses (14\%).
The effect of the bandage on the incidence on incisional complications differs from the results described by Smith et al (2007), who found a reduction rate of $45 \%$ in post-operative incisional complications in horses that had an abdominal bandage applied. It is unclear why the results of their study were not consistent with the results of the 188 horses evaluated in this study. However, they included 85 horses and did not use a standard protocol in closure of the abdominal cavity, which might influence the occurrence of incisional complications (Coomer et al. 2007). They included wound edema and discharge in their results. When taking only purulent wound discharge in account the results might have been different.

Although some authors (Tulleners and Fretz 1983) state that incisional hernias are apparently uncommon in large animals, the results of this study are different (13\%). This might be a matter of definition, while other authors report a 2.8\% (Turner et al. 1988), 5.7\% (Kobluk et al. 1988), 6\% (Wilson et al 1995 ) and a $16 \%$ herniation rate (Gibson et al. 1989). In the literature no reference was made to the size of the hernias or whether they include only visible hernias or also palpable hernias. Our study included the very small hernias of one finger in diameter, the larger ones, as well as the invisible palpable hernias. Because the owners were asked to palpate the belly, it occurred that at the first phone call the owner was very enthusiastic about the wound healing and said no problems had occurred and that the belly of the horse was perfect. However, at the second telephone call, after palpation, some reported of the presence of a small soft spot, which is very indicative for a hernia and which was included as a herniation.

The difference in frequency of occurrence of herniation between ponies and horses might be the consequence of body weight, however, a different inflammatory response as noticed in wound healing of the limb might play a role (Wilmink et al 2003). Although in literature a higher incidence of herniation has been reported in male horses (Gibson et al 1989), the obtained results from this prospective study could not confirm these findings.

More hernias were diagnosed in horses with colic related to the large intestine. This might be the consequence of a larger incision, but could also be due to a higher risk of contamination. However, there was no difference in bacteriological culture of the abdominal fluid between colic caused by the small intestine and the large intestine.

Also, it became clear that the presence of purulent discharge is significantly more of importance in the development of a hernia than edema, which is consistent with findings of others (Rijkenhuizen et al 1994, Mair and Smith 2005, Smith et al. 2007). An inflammatory reaction weakens the sutured abdominal wall and in combination with the intra-abdominal pressure a hernia can develop. However, the fact that horses with edema and purulent discharge have a significant higher risk, does certainly not mean that hernias don't develop in wounds without edema and discharge. Hernias occurred in horses with a transudative wound as well as in horses with a wound healed primarily, a finding also described by Schumacher et al (1981).

A remarkable finding was the influence of the surgeon on the occurrence on wound complications, which was significant. 
Although we considered that basically the surgeons used the same protocol to close the abdominal cavity, it obviously was not. This might be due to the individual suturing technique, meaning the distances between the sutures to the incision site, the distance between the sutures themselves, the tension on the suture and the handling of the soft tissue. Even the size of the surgeon might have an influence as well as the size of the incision made by the surgeon.

In retrospect, the use of the sterile woundpad (Cutisorb) might have reduced the pressure from the bandage on the wound, because its size was quite broad and it is hypothesized that 4 $\mathrm{cm}$ on both sites of the incision was not under direct pressure. The reduced pressure was considered to occur while it was possible to palpate the wound manually. Whether pressure on the wound is essential and might play a role in reducing wound complications should be studied. The application of the bandage applied by Smith et al (2007) is also with the use of padding at the wound site and probably in effectiveness not different from the bandage used in this study.

Factors that were not included in this study, like the cardiovascular parameters, duration of the colic signs, medication, systemic condition, performing a enterotomy or intestinal resection, the post-operative abdominal distension and pain might have had an influence on the occurrence of wound complications (Kobluk et al. 1989, Phillips and Walmsley 1993, Honnas and Cohen 1997, Ingle-Fehr et al. 1997, French et al.2002, Coomer et al. 2005, Mair and Smith 2005), but were not the objective of this study.

In conclusion, the use of bandages does not reduce the incidence of wound dehiscence; no effect was obtained in preventing incisional hernias. Other factors like the intestinal segment involved, probably in relation to the size of the incision, infection and surgical technique seemed to be of more importance in causing complications after abdominal colic surgery. The application of a bandage postoperatively has no advantages on wound healing other than preventing obvious and excessive edema.

\section{Manufacturer's addresses}

1 Elastoplast, Beiersdorf, Amalialaan 126 C,3743 KJ Baarn

2 Betadine Dagra Pharma B.V.. Verrijn Stuartweg 60. 1112 AX Diemen

${ }^{3}$ VidrapeTM 1, Vetin-Aacofarma bv. Industrieweg 75281 RW Boxtel

${ }^{4}$ Cutisorb, Beiersdorf, Amalialaan 126 C,3743 KJ Baarn

\section{Acknowledgement}

The author would like to thank all the colleagues of the University Utrecht who supported this study, especially Dr. W. R.Klein

\section{References}

Anderson S. L., Vacek J. R., Macharg M. A. and Holtkamp D. J. (2011) Occurrence of incisional complications and associated risk factors using a right ventral paramedian celiotomy incision in 159 horses.Vet. Surg. 40, 82-89
Bartmann C. P., Bubeck K., Georgiadis S. and Deegen E.(2003) Verbesserung der Heilung der Bauchwunde nach medianer Laparotomie beim Pferd. Pferdeheilkunde 19, 351-358

Becker M. (1995) Der Bauchdeckenverschluss beim Pferd nach medianer Laparotomie. Tierärztl. Praxis. 13, 325-329

Bischofberger A. S., Braver T., Gugelchuk G. and Klohnen A. (2010) Difference in incisional complications following exploratory celiotomies using antibacterial-coated suture material for subcutaneous closure: Prospective randomised study in 100 horses. Equine Vet. J. 42, 304-309,

Coomer R. P. C., Mair T. S., Edwards G. B. and Proudman C. J. (2007) Do subcutaneous sutures increase risk of laparotomy wound suppuration? Equine Vet. J. 39, 396-399

French N. P., Smith J. E., Edwards G. B. and Proudman C. J. (2002) Equine surgical colic: risk factors for post-operative complications. Equine vet. J. 34, 444-449

Gibson K. T., Curtis C. R., Turner A. S., Mcllwraith C. W., Aanes W. A. and Stashak T. S. (1989) Incisional hernias in the horse: incidence and predisposing factors. Vet. Surg. 18, 360-366

Honnas C. M. and Cohen N. D. (1997) Risk factors for wound infection.following celiotomy in horses. J. Am. Vet. Med. Assoc. 210, 78-81

Ingle-Fehr J. E., Baxter G. M., Howard R. D., Trotter G. W. and Stashak T. S. (1997) Bacterial culturing of ventral median celiotomies for prediction of postoperative incisional complications in horses. Vet. Surg. 26, 7-13

Kobluk C N., Ducharme N. G., Lumsden J. H., Pascoe P. J., Livesey M. A., Hurtig M., Horney F. D. and Arighi M. (1989) Factors affecting incisional complication rates associated with colic surgery in horses: 78 cases (1983-1985). J. Am. vet. med. Ass. 195, 639-642.

Mair T. S. and Smith L. J. (2005b) Survival and complications rates of 300 horses undergoing surgical treatment of colic. Part 1: Short-term survival. Equine vet. J. 37, 296-302

National Academy of Sciences, National Research Council, Division of Medical Sciences, Ad Hoc Committee on Trauma. (1964) Postoperative wound infections: the influence of ultraviolet irradiation on the operating room and of various other factors. Ann. Surg. 2, 1

Phillips T. J. and Walmsley J. P. (1993) Retrospective analysis of the results of 151 exploratory laparotomies in horses with gastrointestinal disease. Equine Vet J. 25, 427-431

Rijkenhuizen A. B. M. and Klein W. R. (1994) Abdominal Bandage after colic surgery. Sense or nonsense? Proc. 3rd Annual Scientific Meeting ECVS, 101-102

Schumacher J., Adams G. and Taylor T. S. (1981) Stainless steel closure of the equine linea alba. Equine pract. 3, 47-53

Smith L. J., Mellor D. J., Marr C. M., Reid S. W. J. and Mair T. S. (2007) Clinical Evidence Article Incisional complications following exploratory celiotomy: does an abdominal bandage reduce the risk? Equine vet. J.39, 277-283

Tulleners E. P. and Fretz P. B. (1983) Prosthetic repair of large abdominal wall defects in horses and food animals. J. Am. Vet. Med. Assoc. 182, 258-262

Turner A. S., Yovich J. V., White N. A., Embertson R. E., Santschi E. M. and Slone D. E. (1988) Continuous absorbable suture pattern in the closure of ventral midline abdominal incisions in horses. Equine vet. J. 20, 401-405

Wilmink J. M., Veenman J. N., van den Boom R., Rutten V. P., Niewold T. A., Broekhuisen-Davies J. M., Lees R., Armstrong S., van Weeren P. R. and Barneveld A. (2003) Differences in polymorphonucleocyte function and local inflammatory response between horses and ponies. Equine Vet J. 35, 561-569

Wilson D. A., Baker G. J. and Boero M. J. (1995) Complications of celiotomy incisions in horses. Vet. Surg. 24, 506-514

Dr. A. B. M. Rijkenhuizen, PhD, dipl. ECVS, dipl. RNVA

Singel 10

3961 CE Wijk bij Duurstede

The Netherlands

a.rijkenhuizen@gmail.com 